\title{
In the Classroom
}

\section{Teaching Pragmatic Competence:}

A Journey from Teaching Cultural Facts
to Teaching Cultural Awareness

Iryna Lenchuk and Amer Ahmed

Pragmatic competence is one of the essential competences taught in the second language classroom. The Canadian Language Benchmarks (CCLB, 2012a), the standard document referred to in any federally funded program of ESL teaching in Canada, acknowledges the importance of this competence, yet at the same time notes the limited resources available to help ESL teachers address it in the classroom. Informed by the theoretical construct of communicative competence and its application to second language learning, the article offers an exemplar of the whats and hows of teaching pragmatics in the ESL classroom. The article stresses the importance of making explicit to the learners the sociolinguistic and sociocultural variables that underlie native speakers' linguistic choices. It is hoped that ESL learners will thus develop a better understanding of the reasons that make native speakers choose one linguistic expression rather than others when performing a certain linguistic act. The speech act of complimenting is used here as an exemplar.

La compétence pragmatique est une des compétences essentielles que l'on enseigne dans un cours de langue seconde. Les niveaux de compétence linguistique canadiens (CCLB, 2012a), le document de référence pour tout programme d'enseignement d'ALS financé par le gouvernement fédéral au Canada, reconnait l'importance de cette compétence mais note la pénurie de ressources pour appuyer les enseignants d'ALS à cet égard. S'appuyant sur la théorie de la compétence communicative et son application à l'apprentissage d'une langue seconde, cet article offre un exemple de ce qu'il faut enseigner, et comment, en matière de compétence pragmatique. L'article souligne l'importance de conscientiser les apprenants quant aux variables sociolinguistiques et socioculturelles qui sous-tendent les choix linguistiques des locuteurs natifs. Ainsi, nous espérons que les apprenants en ALS comprendront mieux les raisons pour lesquelles les locuteurs natifs choisissent une expression linguistique plutôt qu'une autre dans un contexte donné, en l'occurrence l'acte verbal qu'est celui de faire un compliment. 


\section{Introduction}

This article provides the description of a lesson plan that targets the acquisition of pragmatic competence by adult learners of English as a second language (ESL). The proposed techniques included in the lesson plan are informed by the theory of communicative competence originally proposed by Hymes (1972). This theory emphasizes "the language user's knowledge of (and ability for use of) rules of language use in context" (Canale \& Swain, 1980, p. 16). Since then, a number of theoretical models have been developed in order to apply the concept of communicative competence to second language (L2) teaching and assessment (e.g., Bachman, 1990; Bachman \& Palmer, 1996, 2010; Canale \& Swain, 1980). For example, according to Canale and Swain, the successful acquisition of communicative competence by ESL learners includes, among others, the successful acquisition of grammatical, sociolinguistic (pragmatic), and strategic competences.

The theory of communicative competence is emphasized in a number of documents developed by the Centre for Canadian Language Benchmarks (CCLB, 2012a, 2012b, 2013). These documents outline a national standard for planning curricula and assessment procedures in a variety of language programs in Canada, such as the government-funded second language (i.e., English or French) training programs. Of particular interest to this article is the fact that, on the one hand, the documents emphasize the importance of the acquisition of pragmatic competence as one of the communicative competences mentioned above. ${ }^{1}$ On the other, the documents point to the lack of effective resources in teaching pragmatics and acknowledge the central role of ESL instructors in developing their own teaching materials (e.g., CCLB, 2012b, pp. 71-99). Given this, the pressure is on the ESL instructors to develop effective techniques that would facilitate the acquisition of pragmatic competence by ESL learners. Needless to say, this is a challenging task for several reasons. First, ESL instructors should understand what is covered by pragmatics. Second, with this knowledge in mind, they should develop activities that are theoretically sound and pedagogically engaging. This article aims to address the challenge of developing techniques and activities that target teaching pragmatic competence by explaining the whats and whys of teaching pragmatics.

This article is structured as follows. Section 1 defines pragmatics and discusses its relation to culture. It explains the importance of developing techniques and activities that raise learners' cultural awareness of the sociolinguistic variables and cultural values underlying a communicative event. Section 2 provides the description of a lesson plan on how to teach pragmatics-specifically on teaching the speech act of complimenting. This lesson plan is inspired by the ideas presented in Section 1. Section 3 offers conclusions. 


\section{Sociolinguistic and Sociocultural Awareness as Important Prerequisites for the Successful Acquisition of Pragmatic Competence}

Pragmatics studies how language is used in communication; in particular, "how more gets communicated than [is actually] said" (Yule, 1996, p. 3). The field of pragmatics and the way pragmatics is acquired by ESL learners, known as interlanguage pragmatics, has undergone a number of changes (Bardovi-Harlig, 2012). On a micro level, pragmatics is the study of "deixis, conversational implicature, presupposition, speech acts, and conversational structure" (Levinson, 1983, as cited in Bardovi-Harlig, 2012, p. 147). On a macro level, pragmatics can be defined as

the study of language from the point of view of users, especially of the choices they make, the constraints they encounter in using language in social interaction, and the effects their use of language has on other participants in the act of communication. (Crystal, 1997, as cited in Bardovi-Harlig, 2012, p. 147)

Consequently, one might argue that on the micro and macro levels of pragmatics, the linguistic choices of speakers are influenced by the system of values, beliefs, and attitudes shared by the members of a speech community (i.e., by their culture). Therefore, awareness of the sociolinguistic and sociocultural variables underlying a communicative event is an important prerequisite for the successful acquisition of pragmatics by ESL learners.

For the purpose of this article, sociolinguistic variables may include but are not limited to gender, age, and social class (e.g., Thomas et al., 2004). Sociocultural variables are defined as the social values, beliefs, and norms that define a speech community. A communicative event is a social situation, in which an utterance (e.g., the speech act of complimenting) is generated and interpreted by the interlocutors. The interpretation of a speech act depends on the context, which includes the immediate physical world of the interlocutors, as well as the social, cultural, and historical knowledge they possess and may (not) share (on the definition of a communicative context, see Cutting, 2008; Hanks, 2006). A speech act is defined as an utterance intended to perform a certain function (Austin, 1962); in addition to complimenting, other speech acts may include apologizing, greeting, thanking, expressing regrets, and so on.

One way to teach pragmatics is through exposing ESL learners to the linguistic choices of speakers of the target community. This is usually done through exposing the learners to conversational formulas and encouraging them to memorize these formulas. In a similar manner, cultural values that underlie a communicative event can be taught through exposing ESL learners to cultural facts about the target culture, which is usually presented as a homogeneous construct. For example, in a lesson that focuses on the skill 
of negotiating, ESL business students learn how to make an offer and how to respond to an offer. Several expressions are used as examples of refusing an offer (e.g., "That's out of the question!" "No way!" "I'll have to think that over"; Trappe \& Tullis, 2006, p. 65). The follow-up listening and speaking activities that are developed to practice the skill of negotiating do not include any information as to why negotiators might prefer one way of making, accepting, or refusing an offer over another.

In the example presented above, pragmatic competence is developed in a manner similar to implicit grammatical competence, where learners are encouraged to internalize the grammatical, phonetic, and lexical system of the target language without consciously thinking about the grammatical form. This pedagogy is congruent with Communicative Language Teaching (CLT), which is based on the theoretical assumption that conscious attention to and explicit teaching of language forms does not necessarily promote L2 learners from acquiring native-like fluency, and fluency is an important component of meaning-based approaches to L2 teaching. (For a discussion of explicit and implicit language learning, see Sanz \& Leow, 2011; for a more general description of the CLT and its pedagogy, see Brown, 2007, pp. 40-61).

Without denying the importance of the specific pedagogy outlined above, in this article we argue that the acquisition of pragmatic competence is facilitated by conscious attention to and critical awareness of the sociolinguistic and sociocultural variables that underlie the pragmatic behaviour of native speakers. In other words, it is hoped that learners will appreciate the pragmatic behaviour of native speakers much more once they are aware of the system of cultural beliefs, values, and norms that make such behavior in/appropriate. In fact, a pedagogy of L2 teaching that emphasizes the importance of cultural awareness among adult second language learners has already been called for in recent literature on communicative competence. In developing pedagogical implications that resulted from a critically reviewed concept of communicative competence, Celce-Murcia (2007) argues for the importance of culture in language teaching. In particular, she states that "if the goal of language instruction is communicative competence, language instruction must be integrated with cultural and cross-cultural instruction .... with special focus on areas of cultural and intercultural difference" (p. 51).

Another problem with the pedagogical approach briefly outlined above is that it is based on the assumption that culture is a homogeneous construct; therefore, all speakers who belong to the same culture adhere to the same "norm," share the same understanding of appropriateness, and therefore sound alike. Such an oversimplified view of culture is presented in the theory of cultural dimensions, according to which cultures can be neatly categorized into individualistic and collectivistic, low uncertainty avoidance and high uncertainty avoidance, high power distance and low power distance. (For a 
complete list of cultural dimensions and their descriptions, see, for example, Hofstede, Hofstede, \& Minkov, 2010).

The above-mentioned cultural dimensions that are used as criteria for understanding communicative and cultural behaviour are also mentioned in a number of TESL (e.g., DeCapua \& Wintergerst, 2004) and ESL textbooks (see, for example, McKay, 2011). For example, the lesson titled "Society and Culture" (McKay, pp. 156-183) targets the acquisition of cross-cultural communication strategies by L2 learners, and states regarding the so-called high-context culture: "in a high context culture (which includes much of the Middle East, Africa, Asia, and South America) most people are from the same background" (p. 169). Such an oversimplified presentation of the high-context culture does not take into account the cultures and languages of numerous minorities who live in the geographical space outlined by the author. $^{2}$

Taking into account a variety of different cultures and languages, one cannot simply claim, as is done by the author of the ESL textbook mentioned above, that people in the so-called high-context cultures share the same communicative patterns of behavior (i.e., "their communication is often more indirect, more formal, and makes use of flowery language and elaborate speech acts"; McKay, 2011, p. 169). By analogy, one cannot expect a "straightforward" (p. 170) mode of communication from all people who live in the so-called low-context cultures (of which Canada, the United States, and Denmark are cited as examples by the author).

Although presenting L2 learners with generalizations and tendencies about different cultures might be a good starting point, it may also lead to an oversimplified and stereotypical view of cultures that impedes rather than facilitates cross-cultural understanding, which is of great importance in today's globalized world.

The homogeneous view on culture is also challenged by those who believe that cultures are heterogeneous and changing. On a par with language, cultures are understood as symbolic capital "that serve to perpetuate relationships of power and domination [and] distinguish insiders from outsiders ... [They] are a constant site of struggle for recognition and legitimation" (Kramsch, 1998, p. 10).

In view of that, in teaching the culture that underlies people's pragmatic behaviour, ESL instructors might find it more helpful to develop teaching materials that raise learners' awareness of the sociolinguistic and sociocultural variables that affect people's communicative behaviour. In the teaching materials on the acquisition of pragmatic competence, activities that impose the mainstream culture on ESL learners as a normative and homogeneous culture should be substituted by the activities that raise cultural awareness and provide ESL learners with choices they understand and can therefore control (see also Corbett, 2003; Kramsch, 2001). 


\section{A Lesson Plan on Teaching Compliments ${ }^{3}$}

This section provides the description of a lesson plan on teaching micro-level pragmatics; specifically, teaching the speech act of complimenting (Appendix A). ${ }^{4}$ This lesson plan targets intermediate (i.e., Stage II) learners, according to the Canadian Language Benchmarks (CLBs) ${ }^{5}$ : speaking (CLB 5), listening (CLB 6), reading (CLB 5), and writing (CLB 5). It can be used in any language program that follows the framework for L2 teaching outlined in the CLBs (e.g., a Language Instruction for Newcomers to Canada [LINC] program, or a general ESL course in a community college).

The activities included in the lesson plan reflect the ideas discussed in the previous section. In this lesson plan, ESL learners are encouraged to observe and explore the speech act of complimenting. Instead of exposing learners to and asking them to memorize formulaic expressions of compliments used in the mainstream culture, the activities developed in the lesson plan target learners' awareness of the specific sociolinguistic and sociocultural variables that affect the linguistic choices of speakers engaged in the act of complimenting.

The lesson plan starts with a warm-up speaking activity (see Appendix A: Activity 1). The purpose of the activity is to activate the learners' schemata by eliciting information regarding what they already know about compliments. A number of elicitation questions refer to the learners' cultures and languages (e.g., "What do people say to express compliments in your first language?"). The purpose of these questions is to acknowledge the learners' background and to draw their attention to the diversity of cultures and languages that exist in the ESL classroom. The elicitation questions focus learners' attention on the compliments in the target culture as one of many choices available to them as bilingual or multilingual speakers.

In addition, the questions listed in the warm-up speaking activity focus on the sociolinguistic and sociocultural variables behind the act of complimenting in the first language of L2 learners (e.g., "While complimenting someone in your first language, do you take into consideration gender and/or status of the person you are complimenting? In other words, would you compliment a female and male colleague using the same or different language?"). The purpose of these questions is to draw the L2 learners' attention to the hypothesis that, similar to the speech act of complimenting in their first language, compliments in L2 may be subject to a variety of sociolinguistic variables (e.g., gender, social status, power).

The warm-up activity is followed by a reading passage (Appendix A: Activity 2) that focuses on the topic of complimenting (e.g., compliments can be given on someone's appearance, possessions, or personality traits), and the linguistic choices available to speakers to express compliments (e.g., so-called "positive verbs" such as admire and be impressed), thus activating two types of knowledge (grammatical and pragmatic). This reading activity also draws 
the learners' attention to the sociolinguistic variable of gender and how it affects the act of complimenting. In particular, the last paragraph of the reading passage talks about different tendencies identified by sociolinguists in compliments given by female and male speakers. For example, sociolinguists have noticed that female speakers tend to have a personal focus and therefore use the first and second person pronouns while complimenting other people, as in "I love your purse!" or "You look great!", whereas compliments given by male speakers are often impersonal, as in "Nice game!" or "Good job!" Reading this passage helps ESL learners become aware of the sociolinguistic variables (e.g., gender) that affect the act of complimenting in the target culture.

Activity 3 (Appendix A) targets the acquisition of compliment response strategies. In this task, ESL learners have to categorize compliment responses according to specific conversational strategies. These strategies are as follows: (a) accepting a compliment (e.g., "Thank you"), (b) mitigating a compliment (e.g., "It's really quite old") or requesting interpretation (e.g., "You want to borrow this one, too?"). In addition to developing their pragmatic competence, ESL learners work on their strategic competence. Specifically, in order to perform this task successfully, learners need to understand the purpose of a compliment response and its function in a conversational exchange by using their cognitive skills, such as identifying the function of a compliment response and categorizing it according to the criteria identified in the task.

Activity 4 (Appendix A) is developed as a listening exercise. This exercise can be recorded by the instructor in advance or read by the instructor to the learners. The listening exercise discusses the issue of appropriateness in complimenting and demonstrates that the appropriateness of a compliment depends on the cultural values shared in a speech community. For example, the compliment "How fat you are!" is quite acceptable in certain parts of India, a country where being overweight is an indicator of prosperity and health. In contrast, such a compliment is inappropriate in Canada because of the shared perception that "slim is beautiful" (Cutting, 2008, p. 19). The listening exercise also states that in some contexts in the North American mainstream culture, it is appropriate to compliment a person who has something new (e.g., a car, a new article of clothing, a haircut). However, the true importance of such a compliment lies in the fact that the change has been noticed and the addressee is worthy of attention. By listening to the passage and discussing the comprehension questions, ESL learners develop an awareness of the importance of understanding the cultural values that underlie the speech act of complimenting.

The lesson plan on compliments includes a number of speaking exercises in which learners practice giving compliments and responding to them. In the speaking exercise (Appendix A: Activity 5), learners form two concentric circles so that each student is facing a partner. One learner compliments the other and the other learner responds. The outer circle rotates; each learner finds a new partner and repeats the process. This exercise is followed by 
a Discourse Completion Task (DCT; Appendix A: Activity 6; Appendix B). The purpose of this task is to practice giving compliments and responding to them by taking into consideration a specific sociocultural variable (e.g., social status) already present in the script of the DCT. The learners are asked to read a script and respond to the compliment accordingly.

In Activity 7 (Appendix A) ${ }^{6}$ L2 learners watch a video clip from the movie "Annie Hall", where Annie Hall and Alvy Singer, the two main characters in the movie, exchange compliments. The purpose of this exercise is to facilitate a better understanding of complimenting in the target culture. From this episode, L2 students learn that (a) depending on the context of interaction, compliments can be used as a conversational strategy to sustain a conversation; and (b) similar to grammar, a conversation exchange is subject to rules (e.g., if someone gives you a compliment, you may acknowledge it by returning a compliment). In this episode, in order to keep the conversation going, Alvy compliments Annie on her play and, in exchange, Annie returns the compliments, even though she is embarrassed by the trivial and superficial nature of their conversational exchange, "Oh, God, whatta - (laughing) whatta dumb thing to say, right? I mean, you say it, 'You play well', and right away ... I have to say ... well. Oh, oh ... God, Annie" (Allen \& Brickman, 1977a). For homework (Appendix A: Activity 8), learners are asked to collect three to five compliment interactions by complimenting three expert speakers of English. Learners have to jot down the exchange immediately following each conversation. Learners are encouraged to observe the contexts in which these compliments were given in terms of the sociolinguistic variables discussed in their class activities (e.g., gender, cultural background, social status) and in terms of their functions in the conversation exchange and their appropriateness.

The assessment in this lesson plan is done through a post-instructional questionnaire in which learners are invited to reflect on their experiences of learning compliments in English (see Activity 9, Attachment A).

\section{Conclusion}

The activities developed in the lesson plan presented above emphasize the importance of understanding the sociolinguistic and sociocultural choices of speakers. They are meant to demonstrate to the ESL learners how native speakers' linguistic choices are always bound by the social variables (gender, social status, cultural background) of speakers. The exercises incorporate the learners' previous knowledge of their cultures and languages and raise awareness of the specific linguistic choices made by the speakers engaged in the speech act of complimenting. The development of cultural awareness is essential for successful communication and an understanding of the cultures of others in a manner that reflects the social framework of any act of using language. This fact is intuitively well-known, yet regretfully often ignored in our teaching practice. 


\section{Notes}

${ }^{1}$ A note should be made here about the terminology used in the documents developed by the CCLB. The new edition of the Canadian Language Benchmarks (CCLB, 2012a) and a supporting document that explains the framework of communicative competence as a theoretical foundation for the CLBs (CCLB, 2013) do not use the term competence. The only exception found in the document is the reference made to strategic competence. Instead, the term knowledge is used to name the competences (i.e., grammatical, textual, functional, sociolinguistic knowledge, and strategic competence). In the CLBs, the acquisition of pragmatic competence is represented through the acquisition of the two types of knowledge: functional and sociolinguistic. A discussion of the reasons behind the change in terminology and its impact on the theoretical framework and pedagogical practice is outside the scope of this article. For the purpose of this article, the terms pragmatics or pragmatic competence are used, and are defined in section 1.

${ }^{2}$ To cite just one example, in a Middle Eastern country such as Iraq, there are at least three minority groups with their own languages and cultures: (a) Christians who speak different varieties of Syriac, (b) Kurds who speak different varieties of Kurdish (a member of the Indo-Iranian family of languages), and (c) Turkmans, who speak a variety of Turkish. Even amongst Arabs in Iraq who share the same language (i.e., Sunnis and Shi'ites), one can observe differences in cultural and religious beliefs and norms. (For more information on the cultural and linguistic mosaic of Iraq, see Mahmoodi-Bakhtiari, 2006).

${ }^{3}$ Adapted from Lesson Plan for Teaching Compliments (Center for Advanced Research on Language Acquisition, n.d.).

${ }^{4}$ The speech act of complimenting has been chosen as one of the speech acts included in the CLB competency area Interacting with Others, which targets understanding "the gist and some details in moderately complex common and predictable social exchanges (that may express ... offers, invitations and compliments)" (CCLB, 2012a, p. 16).

${ }^{5}$ The 12 CLBs are divided into three stages: Stage I-Basic Language Ability (Benchmarks 1-4), Stage II-Intermediate Language Ability (Benchmarks 5-8), and Stage III-Advanced Language Ability (Benchmarks 9-12) (CCLB, 2012a, p. X).

${ }^{6}$ This activity is partly based on a sample lesson outline proposed by Celce-Murcia (2007, pp. 13-14).

\section{Acknowledgements}

We would like to thank the two anonymous reviewers for many insightful comments and suggestions on a previous draft of this article. These suggestions greatly improved the quality of this article. Any remaining errors are our own.

\section{The Authors}

Iryna Lenchuk is a PhD candidate in the Linguistics and Applied Linguistics program at the Department of Languages, Literatures and Linguistics at York University, Toronto, Ontario. She is also a part-time TESL Instructor at the Faculty of Continuing Education and Training, Seneca College, Toronto, Ontario.

Amer Ahmed is a PhD candidate in the Linguistics and Applied Linguistics program at the Department of Languages, Literatures and Linguistics at York University, Toronto, Ontario.

\section{References}

Allen, W. (Writer/Director), \& Brickman, M. (Writer). (1977a). Annie Hall [Motion Picture]. Retrieved from http://www.dailyscript.com/scripts/annie_hall.html

Allen, W. (Writer/Director), \& Brickman, M. (Writer). (1977b). Annie Hall [Motion Picture].

Retrieved from http://www.youtube.com/watch?v=KFCe1wQeXA0

Austin, J. L. (1962). How to do things with words. London, UK: Oxford University Press. 
Bachman, L. F. (1990). Fundamental considerations in language testing. Oxford, UK: Oxford University Press.

Bachman, L. F., \& Palmer, A. S. (1996). Language testing in practice: Designing and developing useful language tests. Oxford, UK: Oxford University Press.

Bachman, L. F., \& Palmer, A. S. (2010). Language assessment in practice: Developing language assessments and justifying their use in the real world. Oxford, UK: Oxford University Press.

Bardovi-Harlig, K. (2012). Pragmatics in second language acquisition. In S. M. Gass \& A. Mackey (Eds.), The Routledge handbook of second language acquisition (pp. 147-162). New York, NY: Routledge.

Brown, H. D. (2007). Teaching by principles: An interactive approach to language pedagogy (3rd ed.). White Plains, NY: Pearson Education.

Canale, M., \& Swain, M. (1980). Theoretical bases of communicative approaches to second language teaching and testing. Applied Linguistics, 1, 1-47.

Celce-Murcia, M. (2007). Rethinking the role of communicative competence in language teaching. In E. Alcón Soler \& M. P. Safont Jorda (Eds.), Intercultural language use and language learning (pp. 41-57). Dordrecht, Netherlands: Springer.

Center for Advanced Research on Language Acquisition. (n.d.). Lesson plan for teaching compliments. Retrieved from http://www.carla.umn.edu/speechacts/compliments/lessonplan.html

Centre for Canadian Language Benchmarks. (2012a). Canadian Language Benchmarks: English as a second language for adults. Retrieved from http://www.cic.gc.ca/english/pdf/pub/languagebenchmarks.pdf

Centre for Canadian Language Benchmarks. (2012b). CLB support kit. Retrieved from http:// www.language.ca/documents/clb_support_kit_1.pdf

Centre for Canadian Language Benchmarks. (2013). Theoretical framework. Retrieved from http:// www.language.ca/documents/theoretical_framework_web.pdf

Corbett, J. (2003). An intercultural approach to English language teaching. Buffalo, NY: Multilingual Matters.

Cutting, J. (2008). Pragmatics and discourse: A resource book for students (2nd ed.). New York, NY: Routledge.

DeCapua, A., \& Wintergerst, A. C. (2004). Crossing cultures in the language classroom. Ann Arbor, MI: University of Michigan Press.

Hanks, W. (2006). Context, communicative. In K. Brown (Ed.), Encyclopedia of language and linguistics (2nd ed., pp. 115-128). New York, NY: Elsevier.

Hofstede, G., Hofstede, G. J., \& Minkov, M. (2010). Cultures and organizations: Software of the mind: Intercultural cooperation and its importance for survival. New York, NY: McGraw-Hill.

Hymes, D. H. (1972). On communicative competence. In J. B. Pride \& J. Holmes (Eds.), Sociolinguistics (pp. 269-293). Harmondsworth, UK: Penguin.

Kramsch, C. (1998). Language and culture. Oxford, UK: Oxford University Press.

Kramsch, C. (2001). Intercultural communication. In R. Carter \& D. Nunan (Eds.), The Cambridge guide to teaching English to speakers of other languages (pp. 201-207). Cambridge, UK: Cambridge University Press.

Mahmoodi-Bakhtiari, B. (2006). Iraq: Language situation. In K. Brown (Ed.), Encyclopedia of language and linguistics (2nd ed., pp. 23-24). New York, NY: Elsevier.

McKay, I. S. (2011). Have your say!: Communication activities (2nd ed.). Don Mills, ON: Oxford University Press.

Sanz, C., \& Leow, R. P. (Eds.). (2011). Implicit and explicit language learning: Conditions, processes, and knowledge in SLA and bilingualism. Washington, DC: Georgetown University Press.

Thomas, L., Wareing, S., Singh, I., Stilwell Peccei, J., Thornborrow, J., \& Jones, J. (2004). Language, society and power: An introduction (2nd ed.). London, UK: Routledge.

Trappe, T., \& Tullis, G. (2006). Intelligent business coursebook: Upper intermediate business English. London, UK: Longman/Pearson.

Yule, G. (1996). Pragmatics. Oxford, UK: Oxford University Press. 


\section{Appendix A \\ Lesson Plan}

Targeted CLB competency area: Interacting with Others

Lesson objective: Learners will be able to express and respond to compliments.

Targeted stage: Stage II

Targeted CLBs: Speaking (CLB 5), listening (CLB 6), reading (CLB 5), and writing (CLB 5).

\section{Procedures/ tasks}

\section{Activity 1: Warm-up/Speaking Activity}

In small groups, learners discuss the following questions:

What is a compliment? Who is likely to give and receive compliments in your first language? What do people say to express a compliment in your first language? If you compliment someone, are there any topics that should (not) be the object of complimenting (e.g., physical appearance, accomplishments and achievements, new things)? While complimenting someone in your first language, do you take into consideration gender and/or status of the person you are complimenting? In other words, would you compliment a female and male colleague using the same or different language? Would you compliment a co-worker and a close friend using the same or different forms of expression? In the place where you come from, is it appropriate to compliment someone who has a higher social status (e.g., your boss or your teacher)? What language would you use? Are there any taboo compliments (e.g., compliments that you would never say)? Think about a specific example.

When do speakers in Toronto give compliments? What do they give compliments on? Do you give and/or receive compliments in English? Are you always comfortable with the way you exchange compliments in English? If no, when do you feel uncomfortable and why?

\section{Activity 2: Reading}

To introduce the topic of giving and receiving compliments, students read the following passage and answer comprehension questions.

\section{Compliments in North American English}

Major compliment topics can be classified into 3 categories:

1. Compliments on someone's appearance or possessions are the most common type of compliments in English. For example, "Your blouse looks beautiful!" You can also use words, such as nice, good, pretty, and great. Good is often used for performance and nice is mostly used for appearance/attire. "I really love your car!" is an example of a compliment that 
contains a "positive" verb. Like or love are used $90 \%$ of the time in this type of compliments. Some other "positive" verbs that are used would be admire and be impressed.

2. "You did a good job!" and "You are such a wonderful writer!" are examples of compliments on performance/skills/abilities.

3. Such comments as "Good boy!" and "You're so sweet!" are compliments on the addressee's personality traits. This category of compliments occurs less frequently than those on appearance/possessions and performance/ skills/abilities.

Linguists who investigated compliments in North American English have noticed some interesting gender differences. For example, compliments given by female speakers tend to have a personal focus and use the first or the second person pronouns, such as "I love your purse!" or "You look great!" Compliments given by male speakers are often impersonal: "Nice game!" or "Good job!" Women receive and give significantly more compliments to each other than they do to men or than men do to each other. It is interesting to note that compliments can also be used as conversation openers.

\section{Comprehension Questions:}

1. What do people in North America give compliments on?

2. What language structures are used for compliments? Provide an example.

3. What is the difference between compliments that are given by male speakers, and those given by female speakers?

4. Did you find any difference/similarity between your first language and English while expressing compliments?

5. What was interesting/surprising for you?

6. Can you provide an example of a compliment that can be used as a conversation opener?

\section{Activity 3: Compliment Response Strategies}

Students work in groups. Each group is given a set of cards. Students have to sort out the cards according to the following categories of the compliment response strategies: Accept, Mitigate, Request Interpretation.

\section{Responding to Compliments Cards}

- Thanks/ Thank you.

- Yeah, it's my favorite, too.

- Really brings out the blue in my eyes, doesn't it?

- I brought it from my country.

- My brother gave it to me.

- Do you really like them?

- So's yours.

- It's really quite old. 
- I feel fat.

- You want to borrow this one, too?

Activity 4: Listening (The teacher may record or read the following script to the learners.)

\section{"How fat you are!": Giving and Receiving Compliments}

Being slim has a strong positive value among mainstream speakers of American English, and the adjective "thin" (e.g., "You look thin") is interpreted as complimentary in itself in this society. That this is definitely not the case for speakers from other societies around the world is often a cause of some confusion, and even insult, when nonnative speakers are the recipients of such remarks. According to the linguist Joan Cutting, in some parts of India one can compliment a person by saying, "How fat you are!" because being overweight is an indicator of prosperity and health in a country where malnutrition is the norm. In contrast, in Canada it is inappropriate to compliment someone on gaining weight, since the fashion and diet food industries, and probably health education, have conditioned many of us into thinking that "slim is beautiful."

\section{Questions for Discussions:}

1. Does the positive value of being slender apply to both men and women in Canada?

2. Would it be all right to say "You lost some weight, didn't you?" as a compliment? What's the possible danger? Develop a conversation exchange where this compliment will be (in)appropriate. Who are the speakers? Are they friends or co-workers? Are they the same gender? Do they share the same social status? Would you compliment your teacher on losing weight?

It is useful for nonnative speakers to know, for example, that the quality of newness is so highly valued in this society that a compliment is appropriate whenever an acquaintance is seen with something new, whether it is a car, a new article of clothing, or a haircut. The fact that the new appearance may be due to an alteration (such as a new hairstyle or the loss of weight) as well as to a purchase leads us to conclude that the true importance of the comment lies in the speaker's having noticed a change, thereby proving that he or she considers the addressee worthy of attention.

\section{Questions for Discussions:}

1. Do you agree that newness is highly valued in Canada? What about in your country?

2. What would be an example of the "new appearances"? 


\section{Activity 5: Speaking}

Students form two concentric circles; each student is facing a partner. One compliments the other, and the other responds. The outer circle rotates; each student finds a new partner and repeats the process, and they switch roles after practicing sufficiently.

\section{Activity 6: Discourse Completion Tasks (DCTs)}

Students practice giving and responding to compliments using discourse completion tasks (see Appendix B).

\section{Activity 7: Listening/Speaking}

This activity targets students' comprehension of compliments and their responses. In addition, it familiarizes them with an additional function of compliments (i.e., to sustain a conversation). In this activity, students watch a video clip from the movie Annie Hall (Allen \& Brickman, 1997b) in which Alvy Singer and Annie Hall, the two main characters, meet for the first time. First, the students are asked to watch the clip with the volume turned off and to make guesses about the two main characters in the scene based on their nonverbal communication, their clothes, and other contextual clues available to them (e.g., Alvy and Annie's conversation takes place in the lobby of a fitness centre). The students are asked to justify their guesses about the following statements:

Alvy

1. Alvy is an educated man in his thirties.

2. Alvy works at a bank.

3. Alvy works as a comedian.

4. Alvy is not attracted to Annie.

5. Alvy compliments Annie on her play.

6. Alvy wears casual clothes, which is typical for his age and the occasion.

7. Alvy is embarrassed.

\section{Annie}

1. Annie is in her thirties.

2. Annie works as a waitress.

3. Annie is a university professor.

4. Anne plays tennis professionally.

5. Annie is attracted to Alvy.

6. Annie's fashion style is unique.

7. Annie is embarrassed.

8. Alvy and Annie will go on a date.

Students are then asked to reconstruct the dialogue between Alvy and Annie, and to compare their dialogues with an actual conversation from the clip. A script of the conversation of the clip, which is presented below, is provided by the teacher. The students role-play the dialogue. They are encouraged to pay attention to and reproduce in their role plays pauses, gap fillers (e.g., $u h, u m$ ), and other types of nonverbal communication (e.g., laughter, gestures). The teacher explains the contracted forms of the following words used in the dialogue: whatta, gotta, wanna, gonna, goin'. 


\section{Dialogue between Alvy and Annie}

ANNIE: Hi. Hi, hi.

ALVY: Hi. Oh, hi. Hi.

ANNIE: Well, bye. (She laughs and backs up slowly toward the door.)

ALVY: You-you play ... very well.

ANNIE: Oh, yeah? So do you. Oh, God, whatta- (laughing) whatta dumb thing to say, right? I mean, you say it, "You play well," and right away ... I have to say ... well. Oh, oh ... God, Annie. (She gestures with her hand) Well ... oh, well ... la-de-da, la-de-da, la-la. (She turns around and moves toward the door.)

ALVY: Uh ... you-you wanna lift?

ANNIE: Oh, why-uh ... y-y-you gotta car?

ALVY: No, um ... I was gonna take a cab.

ANNIE (laughing): Oh, no, I have a car.

ALVY: You have a car? So ... I don't understand why ... if you have a car, so then-then wh-why did you say "Do you have a car?" ... like you wanted a lift?

ANNIE: I don't ... (laughing) I don't ... Geez, I don't know, I've ... I got this VW out there ... What a jerk, yeah. Would you like a lift?

ALVY: Sure. W-w-w-which way yuh goin'?

ANNIE: Me? Oh, downtown!

ALVY: Down- I'm-I'm goin' uptown.

ANNIE (laughing): Oh, well, I'm goin' uptown, too.

ALVY: Uh, well, you just said you were going downtown.

ANNIE: Yeah, well, I'm, but I ... I mean, I can go uptown, too. I live uptown, but ... uh, what the hell, I mean, it'd be nice having company, you know I mean, I hate driving alone. (Allen \& Brickman, 1977a)

After the role-play, the students are asked to identify a compliment exchange and think about the following questions:

Why does Alvy compliment Anne? Is his compliment original? What purpose does it serve? Why do you think Anne is embarrassed by her response to Alvy's compliment? Does she use specific language, laughter, and/or body language to conceal her embarrassment? In addition to compliments, what other speech acts are used in the dialogue (e.g., greetings, invitations)? Do you think that this compliment exchange is possible in your language? In what situations? What might be similar? What might be different? What do think happens to Alvy and Annie in this movie?

\section{Activity 8: Homework}

Learners should collect 3-5 compliments and responses by sincerely complimenting three expert speakers of the English language. Learners then jot down the interactions immediately following each conversation. Encourage 
the students to observe the circumstances in which these compliments were given and received in terms of gender, social status, appropriateness, and other factors.

\section{Activity 9: Assessment and Future Planning}

Ask the learners to complete the post-instruction inventory individually. The inventory asks the following questions: (a) Write down an imaginary compliment interaction as you would say it. (b) After learning about compliments, how do you feel about giving and receiving compliments in English? (c) Did the classroom information help you to feel more comfortable with giving and receiving compliments? (d) Are you interested in learning about other functions of English? Check the ones you are interested in: greetings, thanking, inviting, refusing invitations, requests, apologies, congratulating, offering condolences, addressing people.

\section{Appendix B \\ Discourse Completion Tasks (DCTs)}

1. You are a team leader; your team has just finished working on a very difficult task for the project. You would like to thank and to compliment the members of your team on an excellent job.

You: Thank you for your excellent job. I am proud of all of you ....

One of your team members:

2. You have started a new course in a community college. You are in the room with some other students waiting for the class to begin. You would like to start a conversation with a young woman sitting next to you.

You: That's a nice iPad case you have there. Where did you get it?

A young woman:

3. Your manager has just returned from a vacation. She looks rested and has a great tan.

You: It's nice to have you back. How was your vacation?

Your manager:

4. You are having lunch with your co-workers. You baked a cake and invited your co-workers to try it.

One of your co-workers: Wow! It's delicious!

You: 